\title{
Assessment of heifer grazing experience on short-term adaptation to pasture and performance as lactating cows ${ }^{1}$
}

\author{
F. Lopes, ${ }^{*}$ W. Coblentz,† P. C. Hoffman, ${ }^{*}$ and D. K. Combs ${ }^{* 2}$ \\ ${ }^{*}$ Department of Dairy Science, University of Wisconsin-Madison 53706 \\ †US Department of Agriculture-Agricultural Research Service, US Dairy Forage Research Center, Marshfield, WI 54449
}

\begin{abstract}
A 3-yr study evaluated the carryover effects of dairy heifer grazing experience on behavior and first-lactation performance as dairy cows. Forty-one Holstein and 23 Holstein-Jersey crossbred calves born between January and April 2008 were randomly assigned to 1 of 4 treatments ( $\mathrm{n}=8$ per group, 2 groups per treatment) in a completely randomized design. Treatments were combinations of managing dairy heifers in confinement (CNF) or on pasture (PST): grazed yr 1 and 2 (PSTPST); grazed yr 1, but confined yr 2 (PSTCNF); confined yr 1 and grazed yr 2 (CNFPST); or confined yr 1 and 2 (CNFCNF). After calving, all heifers on all treatments were grazed as cows in yr 3. In yr 1, PSTPST and PST$\mathrm{CNF}$ heifers were grazed for $41 \mathrm{~d}$ on Italian ryegrass pastures, whereas CNFPST and CNFCNF were housed in bedded-pack pens and fed a TMR. In yr 2, PSTPST and CNFPST heifers grazed Italian ryegrass pasture for $65 \mathrm{~d}$, whereas PSTCNF and CNFCNF remained in confinement. In yr 2, a mid-trial assessment of heifer grazing behavior was made on PSTPST versus CNFPST heifers. Grazing activities were assessed by visual observation and heifer movement measured by portable global positioning system units. Heifers from all treatment groups subsequently calved between January and April in yr 3. All primiparous cows were then allocated to pastures by treatment group, grazed for $61 \mathrm{~d}$, (May through July) in yr 3, with grazing behavior and milk production evaluated while grazing. In yr 2, heifers on the PSTPST treatment spent more time grazing than heifers on the CNFPST treatment (78 vs. $35 \%$ of the time) when first exposed to pasture (d 1). On d 1 to 3, PSTPST heifers walked a greater distance than CNFPST heifers; however, PSTPST and CNFPST heifers had similar daily grazing times and walk-
\end{abstract}

\footnotetext{
Received September 5, 2012.

Accepted January 31, 2013.

${ }^{1}$ Mention of trade names or commercial products in this article is solely for the purpose of providing specific information, and does not imply either recommendation or endorsement by the US Department of Agriculture.

${ }^{2}$ Corresponding author: dkcombs@wisc.edu
}

ing patterns after $3 \mathrm{~d}$ of pasture exposure in yr 2. As lactating cows (yr 3), cows with no (CNFCNF) grazing experience grazed less on d 1 compared with cows with (PSTPST, PSTCNF, or CNFPST) grazing experience. Day-1 grazing times in yr 3 were $62,59,76$, and $13 \%$ of the times for cows with PSTPST, PSTCNF, CNFPST, and CNFCNF grazing experience, respectively. In yr 3 , on $\mathrm{d} 1$ to 3 , cows with previous grazing experience as heifers (PSTPST, CNFPST, and PSTCNF) walked a greater distance than cows without previous grazing experience (CNFCNF). Milk production was lowest on d 1 to 3 for cows with no previous grazing experience (CNFCNF), but average daily milk production was not different overall over the $61 \mathrm{~d}$ of study in yr 3. Results indicate that grazing experiences as a heifer can affect behavior and milk production during a cow's first days on pasture. After a short acclimation period, dairy cows without grazing experience as heifers developed similar grazing behaviors and performance as cows with grazing experience as heifers.

Key words: heifer, grazing behavior, milk production

\section{INTRODUCTION}

Most dairy grazing research conducted at land-grant colleges in the United States has been designed utilizing lactating dairy cows that are normally housed in confinement, which may or may not have previous grazing experience. Grazing activities of ruminants are known to be influenced by environmental variables such as pasture management, type and quality of forage, and pasture supplementation, and these factors can affect forage intake and behavior (forage selection, time spent grazing, pasture rate, and consumption) of grazing ruminants. According to Bandura (1977), grazing skills are refined through repeated performance, and the duration of exposure to a food early in life may not be related linearly to intake of that food later in life (Ortega-Reyes et al., 1987).

Distel and Provenza (1991) observed that cattle and sheep learn to select specific forages, and remember experiences from early pasture exposure, and will select the same specific forages and forbs later in life. Expe- 
Table 1. Treatment scheme used during the $3 \mathrm{yr}$ of the experiment ${ }^{1}$

\begin{tabular}{lllll}
\hline & & \multicolumn{2}{c}{ Treatment $^{2}$} \\
\cline { 2 - 4 } Item & PSTPST & PSTCNF & CNFPST & CNFCNF \\
\hline Heifers & PST (16) & PST (16) & CNF (16) & CNF (16) \\
yr $1^{3}$ & PST (16) & CNF (16) & PST (16) & CNF (16) \\
yr 2 & Primiparous cows & PST (14) & PST (14) & PST (15) \\
yr $3^{5}$ & PST (15) & PST \\
\hline
\end{tabular}

${ }^{1}$ The numbers in parentheses represent the number of animals per treatment group, per year.

${ }^{2} \mathrm{PST}=$ pasture $\mathrm{CNF}=$ confinement.

${ }^{3} 2008$ : calves at approximately 6 mo old. The grazing period was September 9, 2008, to October 14, 2008.

${ }^{4}$ 2009: heifers at approximately 1 yr old. The grazing period was June 22, 2009, to September 17, 2009.

${ }^{5}$ 2010: primiparous cows. The grazing period was May 17, 2010, to July 20, 2010.

riences obtained as a young animal have been shown to affect diet selection, grazing behavior, and animal productivity months or years later in sheep and cattle (Hatfield et al., 1992; Ortega-Reyes and Provenza, 1993). Provenza (1995) reported that ruminants exposed to pasture acquire their foraging skills at an early age and graze more efficiently than animals that have not been exposed to pasture. However, much of the aforementioned research was conducted in rangeland grazing systems, where animals are exposed to toxic plants as well as forbs and grasses that vary greatly in nutritional value.

In contrast, grazing dairy cattle pastures typically contain high-quality grasses and legumes. It is not known if early grazing experiences affect grazing behavior or milk yield of dairy cows when grazing highquality pasture. It is also not clear how long it takes for dairy cows with no previous grazing experience as heifers to adapt to lactation pasture management systems. As a result, the objective of this study was to assess (1) how dairy cows adapt to pasture and whether grazing at a young age influences how lactating cows graze, (2) if previous experience affects grazing behavior, and (3) how lactating cows with no previous grazing experience (cows raised from birth in confinement) behave relative to animals with prior grazing experience in the short term (first few days on pasture) and long term (after several weeks).

\section{MATERIALS AND METHODS}

\section{Experimental Design, Animals, and Treatments}

Forty-one Holstein and 23 Holstein $\times$ Jersey $(7 / 8$ Holstein $\times$ Jersey crosses) weaned calves that were born between January and April 2008 were assigned randomly to 1 of 8 groups comprising 8 animals each. The 8 groups were then assigned randomly to 1 of 4 treatment groups. The treatments were (1) heifers as- signed to pasture (PST) as weaned calves (yr 1, 2008) and as yearlings (yr 2, 2009; 6 Holstein and 9 Holstein $\times$ Jersey; PSTPST); (2) heifers assigned to PST as weaned calves (yr 1, 2008), but then housed in confinement (CNF) as yearlings (yr 2, 2009; 8 Holstein and 8 Holstein $\times$ Jersey; PSTCNF); (3) heifers housed in CNF as weaned calves (yr 1, 2008), and then assigned to PST as yearlings (yr 2, 2009; 7 Holstein and 9 Holstein $\times$ Jersey; CNFPST); or (4) heifers housed in $\mathrm{CNF}$ as weaned calves (yr 1, 2008) and yearlings (yr 2, 2009; 8 Holstein and 8 Holstein $\times$ Jersey; CNFCNF). All treatment groups were assigned to summer pasture as lactating cows (yr 3, 2010; Table 1).

The first 2 yr (2008 and 2009) of the study were conducted at the University of Wisconsin's Integrated Dairy Research facility located in Marshfield. Each group of 8 heifers was housed in $4.5-\times 9.0-\mathrm{m}$ pens within a 2-row bedded-pack barn, and allotted $30 \mathrm{~m}^{2}$ of resting area that was bedded with sawdust daily. Each heifer had access to $0.75 \mathrm{~m}$ of bunk space in a neck-rail bunk line, except when the heifers were assigned to summer pastures. Heifers were fed TMR (1 time/d) at $1100 \mathrm{~h}$ in CNF. Approximately $6 \mathrm{wk}$ before their expected calving date, heifers were transported from the Integrated Dairy Heifer Research Facility in Marshfield to the Dairy Research Facility in Arlington, Wisconsin, where the third year of the experiment was conducted. Prior to calving, heifers were comingled in a loose housing facility bedded with straw and fed a prepartum ration (87:13 conserved forage:concentrate) until parturition. All heifers calved between January and April 2010. After calving, heifers were comingled in a freestall barn until May 17, 2010, when the lactation phase of the $3-y r$ trial was initiated.

\section{Pastures}

At the Marshfield facility, 7 ha of Italian ryegrass (Lolium multiflorum) pasture were established for graz- 
ing during the heifer phases of the trial (yr 1 and 2). At the Arlington facility, 14 ha of pasture that were seeded with $41.5 \%$ tall fescue (Festuca arundinacea 'Bariane'), 41.5\% meadow fescue (Festuca pratensis 'Pradel'), and $17.0 \%$ Kopu II white clover (Trifolium repens) were established for grazing from spring to summer of yr 3 (2010).

Heifers were managed on an intensive rotational grazing system, where the average residence time in each paddock was (mean $\pm \mathrm{SD}) 8.3 \pm 2.31 \mathrm{~d}$, and the mean forage availability across all evaluation dates (n $=19$ ) and paddocks was (mean \pm SD) $1,723 \pm 857.2$ $\mathrm{kg} / \mathrm{ha}$ as measured with a calibrated rising-plate meter (Bransby et al., 1977). The rising plate was dropped approximately 30 times per pasture with equal distribution across all paddocks. Potential forage DMI was calculated as a percent of $\mathrm{BW}(1.9 \%$ of $\mathrm{BW}$ for heifers and $2.3 \%$ of BW for lactating heifers). Pasture allocation was adjusted so that potential forage DMI was approximately $30 \%$ of available pasture for nonlactating heifers and $40 \%$ for primiparous cows. Water was offered ad libitum in confinement at both grazing locations, and in the access walkway to the pasture for lactating cows at Arlington. At Marshfield, nonlactating heifers had continuous access to fresh water for ad libitum consumption in all pastures. No shade was provided in the pasture. When the temperature was $>32.2^{\circ} \mathrm{C}$, all heifers and cows were removed from the pastures and maintained inside the barn.

Pasture samples at Arlington were collected by tossing a $1.0-\mathrm{m}^{2}$ frame randomly at 4 locations per paddock before and after grazing. At Marshfield, pasture samples were clipped in association with rising-plate meter drops within each pasture. Generally, a 25-g sample was clipped immediately adjacent to the rising plate meter after every other meter drop. Herbage was cut to a 5 -cm stubble height, and placed in a $60^{\circ} \mathrm{C}$ forced-air oven for $72 \mathrm{~h}$ and ground through a $2-\mathrm{mm}$ screen in a Wiley mill (Arthur H. Thomas Co., Philadelphia, PA). Pregrazing samples were sent to Dairyland Laboratories Inc. (Arcadia, WI) where the samples were analyzed for DM (method 930.15; AOAC International, 1995), CP (method 954.01; AOAC International, 1995), and NDF (with residual ash) using $\alpha$-amylase and sodium sulfite (Van Soest et al., 1991).

\section{Year 1: Exposure to Pasture}

During yr 1, heifers allocated to PSTPST and PSTCNF treatments were allowed to graze Italian ryegrass pastures from September 9 to October 14. At the same time, heifers from CNFPST and CNFCNF treatments were housed in a confinement bedded-pack barn. At the beginning of the study, heifers averaged $179 \pm 31 \mathrm{~kg}$ of BW and $2.5 \pm 0.2 \mathrm{BCS}$ for all treatments.

Grazing heifers were only supplemented at the pasture once per day with approximately $0.5 \mathrm{~kg}$ of ground corn and mineral mix/head per day. During the first $3 \mathrm{~d}$ of the study, heifers were returned to the barn at $1900 \mathrm{~h}$ and remained there overnight. Confined heifers allocated to CNFPST and CNFCNF treatments were offered approximately $5 \mathrm{~kg}$ of TMR DM/head per day. The nutrient composition of pasture forage and TMR are presented in Table 2. During the grazing exposure period, BW and BCS were recorded monthly for heifers from all 4 treatments. After conclusion of the grazing period (October 14, 2008), all heifer treatment groups were housed ( 8 heifers/pen) in CNF and fed a TMR until the following grazing season.

\section{Year 2: Influence of Prior Grazing Experience}

During the second study year, heifers assigned to PSTPST and CNFPST treatments grazed Italian ryegrass pasture from June 22 to September 17, 2009. Heifers assigned to PSTCNF and CNFCNF treatments were housed in the bedded-pack barn during the grazing season, and were not allowed access to PST. At the beginning of the grazing season, heifers averaged $400 \pm$ $44.0 \mathrm{~kg}$ of BW and $3.5 \pm 0.1 \mathrm{BCS}$.

Grazing heifers were supplemented as in yr 1. During the first $3 \mathrm{~d}$ of study during yr 2, heifers (PSTPST and CNFPST) returned to the barn at $1900 \mathrm{~h}$ to stay overnight until they were adapted to the electric fencing system; after d 3 heifers remained on the PST continuously. Heifers assigned to PSTCNF and CNFCNF treatments were housed in a bedded-pack barn and fed $8 \mathrm{~kg}$ of TMR DM/head per day. Nutrient compositions of pasture forage and TMR are presented in Table 2. Body weight and BCS were recorded monthly for all 4 treatments. After the grazing was terminated (September 17, 2009), all heifers were housed in CNF and offered TMR until they were transferred to the Arlington Experimental Station before calving.

\section{Year 3: Influence of Prior Grazing Experience on Milk Production}

The third year (lactation phase) of the trial was conducted at the Integrated Dairy Research Facility in Arlington, Wisconsin. Primiparous cows grazed from May 17 to July 20, 2010. The objective of the lactation phase of the experiment was to determine how previous grazing experience as heifers affected grazing behavior and animal movements of lactating cows. Cows originally assigned to PSTPST, PSTCNF, CNFPST, or CNFC- 
Table 2. Chemical composition of pasture and supplements of each year of experiment

\begin{tabular}{|c|c|c|c|c|c|c|}
\hline \multirow[b]{2}{*}{ Item } & \multicolumn{4}{|c|}{ Heifers } & \multicolumn{2}{|c|}{ Lactating cows } \\
\hline & $\begin{array}{c}\text { yr 1 } \\
(2008)\end{array}$ & SD & $\begin{array}{c}\text { yr } 2 \\
(2009)\end{array}$ & SD & $\begin{array}{c}\text { yr } 3 \\
(2010)\end{array}$ & SD \\
\hline \multicolumn{7}{|c|}{ Italian ryegrass pasture $^{1}$} \\
\hline DM, $\%$ & 22.3 & 2.0 & 21.9 & 3.1 & - & - \\
\hline $\mathrm{CP}, \%$ of $\mathrm{DM}$ & 18.7 & 1.4 & 19.3 & 4.5 & - & - \\
\hline NDF, $\%$ of DM & 48.7 & 5.4 & 47.0 & 4.8 & - & - \\
\hline \multicolumn{7}{|l|}{ Mixed pasture $^{2}$} \\
\hline DM, \% & - & - & - & - & 22.0 & 3.0 \\
\hline $\mathrm{CP}, \%$ of $\mathrm{DM}$ & - & - & - & - & 19.2 & 4.3 \\
\hline NDF, $\%$ of DM & - & - & - & - & 49.7 & 4.9 \\
\hline \multicolumn{7}{|l|}{$\mathrm{TMR}^{3}$} \\
\hline DM, \% & 34.0 & 2.0 & 35.5 & 5.5 & - & - \\
\hline $\mathrm{CP}, \%$ of $\mathrm{DM}$ & 15.7 & 1.1 & 14.9 & 1.8 & - & - \\
\hline NDF, $\%$ of DM & 40.1 & 4.2 & 52.7 & 4.1 & - & - \\
\hline \multicolumn{7}{|l|}{ Concentrate $^{4}$} \\
\hline $\mathrm{DM}, \%$ & 87.6 & 0.2 & 88.0 & 0.4 & 90.6 & 0.3 \\
\hline $\mathrm{CP}, \%$ of $\mathrm{DM}$ & 8.8 & 0.7 & 9.0 & 0.8 & 17.3 & 0.5 \\
\hline $\mathrm{NDF}, \%$ of $\mathrm{DM}$ & 10.7 & 0.5 & 10.9 & 0.3 & 6.7 & 0.8 \\
\hline
\end{tabular}

${ }^{1}$ Composition of pastures at the Marshfield Integrated Dairy Research (IDR) facility (Marshfield, WI).

${ }^{2}$ Composition of mixed pasture (composed of tall fescue, meadow fescue, and white clover) at the Arlington IDR facility (Arlington, WI).

${ }^{3}$ Total mixed ration composition (fed to animals in confinement): $45.2 \%$ grass silage (haylage, oatlage, and sorghum sudan), $53.60 \%$ corn silage, $0.84 \%$ shelled corn, and $0.34 \%$ low-phosphorous mineral.

${ }^{4}$ Concentrate composition: 2008 and 2009: $90 \%$ ground dry corn and 10\% salt with trace minerals and vitamins A, D, and E; 2010: $78.9 \%$ ground dry corn, $11.3 \%$ soybean meal, $5.6 \%$ corn gluten meal, $1.4 \%$ calcium carbonate, $0.8 \%$ magnesium oxide, $1.4 \%$ salt with trace minerals, and $0.6 \%$ vitamins $\mathrm{A}, \mathrm{D}$, and $\mathrm{E}$.

$\mathrm{NF}$ treatments as heifers were divided into 2 groups $(\mathrm{n}=8 /$ group $)$ within treatment, and each group was randomly assigned to one of the paddocks. Heifers assigned to the original treatment groups were not mixed with heifers from the other treatment groups. Each treatment group was separated from other groups by an empty paddock to avoid external group influences. Daily availability of pasture was $25 \mathrm{~kg}$ (DM basis)/cow per day at the beginning of the study and decreased to $18 \mathrm{~kg} /$ cow per day by the middle of July. On the first day of grazing, primiparous cows averaged DIM was $97 \pm 39 \mathrm{~d}$ for PSTPST cows, $100 \pm 36 \mathrm{~d}$ for PSTCNF cows, $86 \pm 47 \mathrm{~d}$ for CNFPST cows, and $85 \pm 43 \mathrm{~d}$ for CNFCNF cows, and average milk yield was $32.7 \pm 5.0$ $\mathrm{kg}$ for PSTPST cows, $27.5 \pm 8.4 \mathrm{~kg}$ for PSTCNF cows, $32.7 \pm 3.9 \mathrm{~kg}$ for CNFPST cows, and $28.8 \pm 5.6 \mathrm{~kg}$ for CNFCNF cows. Average BW was $578 \pm 48.0 \mathrm{~kg}$.

During the first week, groups of lactating cows were exposed to the pasture on different days. Heifers assigned to PSTCNF and CNFCNF treatments grazed on $\mathrm{d} 1,2$, and 3 and then returned to confinement for 3 d. Heifers from PSTPST and CNFPST treatments grazed on d 4, 5, and 6 . On d 7 , all treatments grazed at the same time. This procedure was adopted to improve the quality of data recorded, as it would be difficult to intensively evaluate all 64 cows at the same time in the period that we expected to find the largest differences.
Cows were allowed to graze approximately $19 \mathrm{~h} / \mathrm{d}$, and were milked daily at 0400 and $1530 \mathrm{~h}$. After each milking, cows were offered half (4 kg of DM/cow per day) of their daily allowance of grain supplementation. Pasture and supplement composition are presented in Table 2.

\section{Animal Behavior Measurements}

To evaluate how previous grazing experience affected animal behavior and activity, heifer movements and distance walked were recorded on selected days during yr 2 and 3. On each observation day, heifers were monitored visually and activity was recorded at 15-min intervals (Gary et al., 1970) for 9- and 8-h periods, respectively. To ensure that the presence of the observer did not interfere with animal behavior, the measurements were taken from a 3.5-m-tall scaffold positioned at least 30 $\mathrm{m}$ from the nearest paddock fence. Animal activity was classified as either walking, grazing, laying, drinking, or standing. All the animal activity was recorded by the same observer during yr 2 and 3.

During yr 2, heifer movements and their distance walked also were recorded by portable global positioning system (GPS) units (Trackstick II; Telespial Systems Inc., Marina Del Rey, CA), which were attached to neck collars on each heifer at $0600 \mathrm{~h}$ for 5 consecutive 
mornings. The GPS units recorded the location and movement of each heifer for $8 \mathrm{~h}$, beginning at 0700 and ending at $1500 \mathrm{~h}$. At that time, heifers were returned to the barn, and the GPS units were removed; heifers then remained in the barn until the next morning, and no feed was offered in the barn. After the first week of the experiment, heifers remained on the PST continuously. After the first week, animal activity and movements were recorded during 7 evaluation periods that were scheduled every 2 wk from July through August of 2009; the length of each evaluation was $8 \mathrm{~h}$ per day for 2 consecutive days.

During yr 3 of the experiment, measurements followed the same general protocol as yr 2, but the GPS units were attached to the cows' neck collars during the morning milkings and removed during the afternoon milking. Data were recorded 1, 2, 3, 4, 5, 18, 19, 32, 33,60 , and $61 \mathrm{~d}$ after cows started the grazing season.

\section{Milk Production}

Milk production was recorded daily throughout the grazing period of yr 3; however, only data recorded 1 , $2,3,4,5,18,19,32,33,60$, and $61 \mathrm{~d}$ after grazing was initiated were used in the statistical analysis. Milk samples were collected at 4 consecutive milkings from d 10 (p.m.) through 12 (a.m.) of each month and analyzed for fat, protein, lactose, SNF, and MUN content by AgSource Milk Analysis Laboratory (Menomonie, WI). Solids-corrected milk and energy output in corrected milk were calculated based on NRC (2001).

All animal handling procedures were approved by the Research Animal Resource Committee (IACUC A01356) of the University of Wisconsin.

\section{Statistical Analyses}

Data were analyzed using PROC MIXED of SAS (SAS Institute, 2004) for a completely randomized design. Kenward-Rogers adjustment for calculation of denominator degrees of freedom and least squares means were compared by the Tukey test. Significance was declared at $P \leq 0.05$. The model used to analyze milk production, as well as animal activity and movement, had to account for repeated measures taken on the same animal; therefore, this model included the fixed effects of treatment, day, and their associated interaction; the random effect was groups of heifers (experimental unit). Spatial power [SP (POW)] covariance structure was used on those variables because of an unequal sampling time. Analysis of milk composition, $\mathrm{BW}$, and BCS variables used the covariance structure type autoregressive [AR (1)] due to the equally spaced sampling times. The SLICE option was used to com- pare treatment differences at individual days when the treatment day interaction was significant.

\section{RESULTS AND DISCUSSION}

\section{Forage and Concentrate Composition}

The composition of pastures, TMR, and concentrate during yr 1, 2, and 3 are summarized in Table 2 . The $\mathrm{NDF}$ and $\mathrm{CP}$ concentrations of Italian ryegrass and mixed pastures were similar during the 3 -yr experiment. Those characteristics indicate high-quality forage, and were expected for temperate forages managed with relatively intensive management.

\section{Year 1: Exposure to Pasture}

The first year of the experiment was simply to expose 2 groups of heifers to a grazing environment. Heifers assigned to treatments PSTPST and PSTCNF remained on the pasture for $41 \mathrm{~d}$, whereas CNFPST and CNFCNF heifers were housed continuously in confinement. At the beginning of the trial, the mean heifer BW were $183 \pm 59.2$ and $177 \pm 77.1 \mathrm{~kg}$ for grazed (PSTPST and PSTCNF) and confinement (CNFPST and CNFCNF) heifers, respectively; no difference $(P>0.05)$ was detected between heifer groups. At the conclusion of the 41-d grazing period, mean BW were $211 \pm 59.3$ and 213 $\pm 60.1 \mathrm{~kg}$ for PST and CNF heifer groups, respectively, which did not differ $(P>0.05)$ between groups.

The pasture exposure period of $41 \mathrm{~d}$ during yr 1 was longer than other studies devised to evaluate learning behavior of young ruminants. Flores et al. (1989) exposed lambs to pasture for $2 \mathrm{~h} / \mathrm{d}$ in the morning for 15 d. Green et al. (1984) exposed lambs to wheat (Triticum aestivum) pasture for $1 \mathrm{~h} / \mathrm{d}$ over $5 \mathrm{~d}$ to test the impact of prior experience on feed intake 3 yr later.

\section{Year 2: Heifer Grazing Behavior and Growth Performance}

During yr 2, it was possible to evaluate the carryover effects of past grazing experience (yr 1) on current (yr 2) heifer grazing behavior. Activity for heifers that grazed during yr 2 (PSTPST and CNFPST) are presented in Table 3. The experienced (PSTPST) heifers that grazed during yr 1 spent more time grazing on $\mathrm{d}$ 1 than the inexperienced (CNFPST) heifers (78.1 vs. $35.4 \% ; P<0.05$ ). On d 2 and 3 , heifers were removed from the pasture at $1300 \mathrm{~h}$ due to the high temperature, which resulted in just $6 \mathrm{~h}$ of grazing. During those days, heifers spent the average of 62.8 and $50.2 \%$ of their time engaged in grazing activity for the PSTPST and CNFPST treatments, respectively, which represented a 
numerical decrease of grazing time for PSTPST heifers, and an increase for CNFPST heifers compared with d 1. On d 4, heifers from both treatments showed a dramatic increase in grazing time compared with $\mathrm{d} 2$ and 3. This behavior may be explained on the basis of hunger caused by the low forage intake during the previous $2 \mathrm{~d}$. However, after the first day of experiment, no further differences were observed for time spent grazing between heifers assigned to the PSTPST and CNFPST treatments (Table 3 ). The difference in time spent grazing between heifers allocated to PSTPST and CNFPST treatments that was reported on $d 1$ suggests that heifers with previous grazing experience (PSTPST) remembered how to graze, because these heifers started grazing immediately upon exposure to the pasture during yr 2. In contrast, heifers (CNFPST) with no previous grazing experience exhibited a clear reluctance to graze on d 1. Similar results were found by Ramos and Tennessen (1992), when lambs with previous experience started to graze immediately and grazed for most of their allotted time on pasture ( $>90 \%)$ compared with inexperienced lamb groups during the first $5 \mathrm{~d}$ of pasture exposure. However, lambs were observed for only $0.5 \mathrm{~h} / \mathrm{d}$ during that 5 -d time interval.

Data from several studies evaluating animals with previous grazing experience compared with those without experience found that inexperienced sheep (Arnold, 1970; Arnold and Maller, 1977; Gluesing and Balph, 1980), goats (Provenza and Malechek, 1986), and cattle (Hodgson, 1971; Hodgson and Jamieson, 1981) placed in a new pasture environment spent as much as $20 \%$ more time eating, but ingested as much as $40 \%$ less food than animals with previous grazing experience. In our study, DMI was not measured, but experienced (PSTPST) heifers spent approximately $78 \%$ of the $9-\mathrm{h}$ observation period foraging and grazing on $\mathrm{d} 1$, whereas the inexperienced (CNFPST) heifers grazed for only $35 \%$ of the observed period (Table 3 ).

On d 1, heifers from neither treatment were observed lying down during the $9 \mathrm{~h}$ that heifer activities were recorded (Table 3). For both groups, time spent lying increased after the first week on pasture; from d 8 through 65, groups spent between 17.0 and $46.0 \%$ of the 9-h observation period lying down. However, time spent lying in the pasture was significantly less for CNFPST heifers $(P<0.05)$ than PSTPST heifers only on $d 15$ and 50. The time spent for other activities, such as drinking, standing, and walking, differed significantly between PSTPST and CNFPST heifers only on d 1, 2 , and 3 (Table 3 ). The reduced time spent lying down during the first days of the experiment could be attributed to the high temperature encountered mainly on d 2 and 3 of the trial during yr 2. During those days, all heifers were observed spending more time standing.

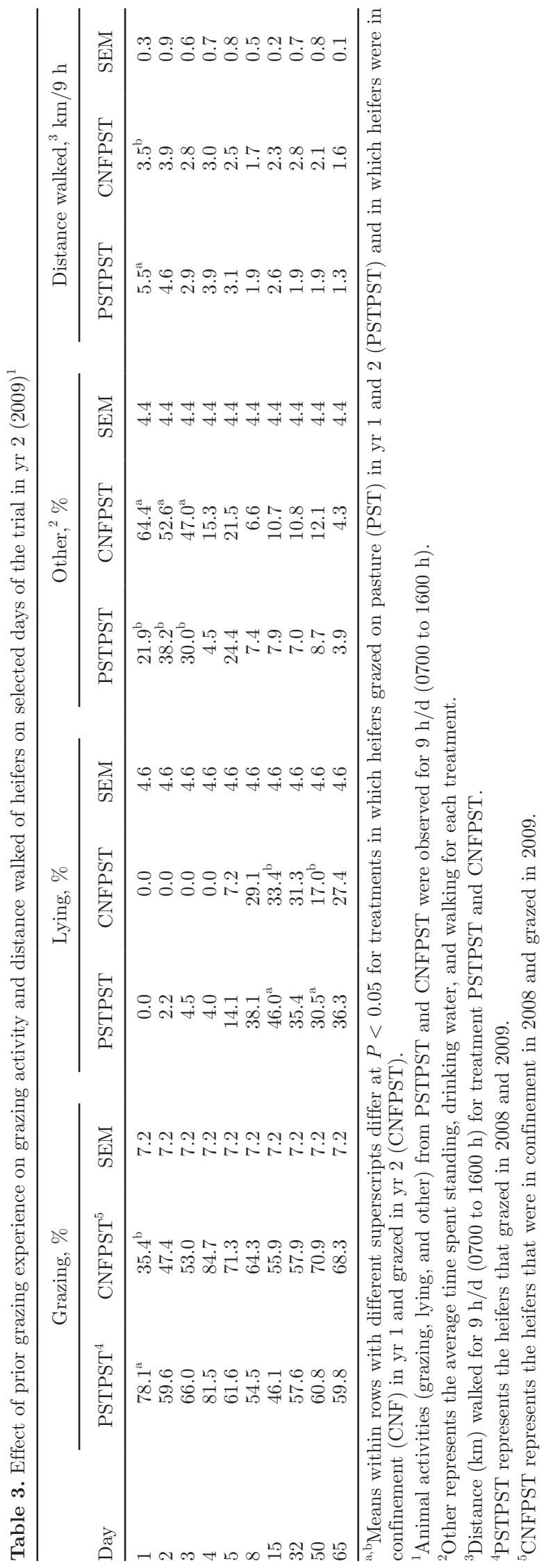

Journal of Dairy Science Vol. 96 No. 5, 2013 
The average kilometers walked during the 9-h observation period by PSTPST and CNFPST heifers during yr 2 are reported in Table 3. Data reflect movements of cattle while on pasture; movements associated with walking to and from the barn and within the barn were not used in this analysis. Heifers assigned to the PSTPST treatment group walked further (5.5 vs. 3.5 $\mathrm{km} ; P<0.05)$ than CNFPST heifers on $\mathrm{d} 1$. On the following days of the experiment, the PSTPST treatment group decreased the distance walked and spent more time lying down. The CP heifers also decreased the distance walked by d 3, which coincided with the time point when heifers started spending more time grazing. After d 1, no statistical difference was found in kilometers walked per day between PSTPST and CNFPST heifers (Table 3). As the grazing season progressed, both groups reduced distance walked per 9-h observation period. By d 8, both groups had reduced the distance walked to approximately $2 \mathrm{~km}$ during the elapsed 9-h observation period. Paddock size varied slightly during yr 2, but no direct relationship between distances walked and paddock size was observed for this study.

The mean forage availability, measured as biomass above 5 -cm stubble height, was $3,588 \pm 631.1 \mathrm{~kg} / \mathrm{ha}$ in mid June, but decreased to $1,356 \pm 45.0 \mathrm{~kg} /$ ha by late July. Forage availability did not seem to affect grazing behavior. Arave and Albright (1981) found that grazing and walking time increased in response to decreased forage availability. In the present study, after heifers adapted to the pasture, the grazing time remained constant between heifer groups, and the time spent walking decreased (Table 3).

The movement pattern of one heifer chosen randomly from each treatment group during the first $5 \mathrm{~d}$ of the trial in yr 2 is shown in Figure 1. Because all heifers moved as a group, the figures attempt to give a general idea of how the pattern of movements differed between treatments. Each dot on the figure represents a movement of the heifers as detected by GPS. Paddock entrance gates were located in the bottom left corner of each figure and water tanks were located at the top right or left of each paddock. The experienced (PSTPST) heifers walked throughout the whole paddock, but the inexperienced (CNFPST) heifers spent most of their time near the gate during the first $4 \mathrm{~d}$ (Figure 1a). The white dots indicate areas where heifers spent more than 1 min without moving, and were concentrated around gates and water tanks in the paddocks where the inexperienced (CNFPST) heifers were assigned. On d 5 (Figure 1e), heifers from both treatments showed similar movement patterns in the pasture. The data suggest that experienced (PSTPST) heifers initially walked further and recognized the pad- dock, and selected specific patches within the paddock to graze. This further suggests that they remembered how to graze. In contrast, inexperienced (CNFPST) heifers spent about $64 \%$ of the observed period walking to water or standing by the gates during the first days of pasture exposure (Table 3). The difference in behavior between experienced (PSTPST) and inexperienced (CNFPST) heifers may be explained by spatial memory, which was defined by Larry et al. (1999) as an animal's ability to remember where it has foraged, and to use that information to determine where it will travel and forage in the future. For example, when cattle are exposed to the pasture, they explore the area to identify the quantity and quality of forage available (Larry et al., 1999).

Initial BW was similar $(P>0.05)$ among treatments (403.2, 402.6, 406.6, and $392.0 \mathrm{~kg}$ for PSTPST, PSTCNF, CNFPST, and CNFCNF, respectively). Likewise, final BW was not different $(P>0.05)$ among treatments $(465.30,483.15,457.05$, and $456.43 \mathrm{~kg}$ for PSTPST, PSTCNF, CNFPST, and CNFCNF, respectively). Respective ADG for these heifer groups were $0.70,0.85,0.60$, and $0.70 \mathrm{~kg} / \mathrm{d}$, with those for CNFPST heifers being significantly less than those for PSTCNF heifers. Distel and Provenza (1991) observed that inexperienced goats lost an average of $4 \mathrm{~kg}$ when exposed to a blackbrush diet, whereas no change in BW was reported for goats with previous grazing experience.

\section{Year 3: Influence of Prior Grazing Experience on Milk Production and Cow Activity}

By yr 3 of the experiment, 8 heifers had been removed from the trial due to reproductive problems; 3 heifers from CNFCNF, 2 heifers from CNFPST, 1 heifer from PSTPST, and 2 heifers from the CNFPST group; therefore, only 56 heifers completed the experiment. During yr 3 , various cow activities on pasture were recorded for $8 \mathrm{~h} / \mathrm{d}$ on selected days (Table 4 ). On d 1 , cows spent 62 , 59,76 , and $13 \%$ of their time grazing for the PSTPST, PSTCNF, CNFPST, and CNFCNF treatment groups, respectively, with CNFCNF cows spending significantly less time grazing than the other treatment groups. The PSTCNF treatment group also grazed less than CNFPST cows. On d 2 and 3, CNFCNF cows increased the time spent grazing to 35 and $24 \%$, respectively, but these inexperienced grazing cows still grazed less than cows that had prior grazing experience (PSTPST, PSTCNF, and CNFPST). On d 4, inexperienced cows $(\mathrm{CNFCNF})$ also spent less time grazing $(P<0.05)$ than PSTPST, PSTCNF, and CNFPST cows. Time spent grazing by cows increased for all treatments at d 5, being greater for PSTCNF than for the PSTPST, CNFPST, or CNFCNF treatments $(P<0.05)$. After 5 


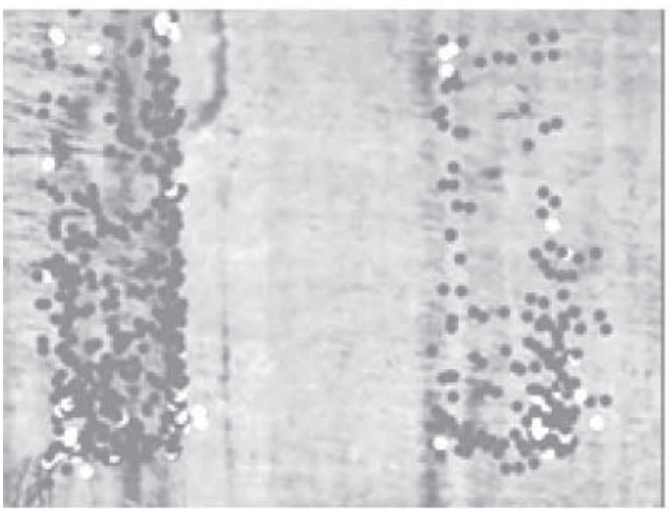

(a)

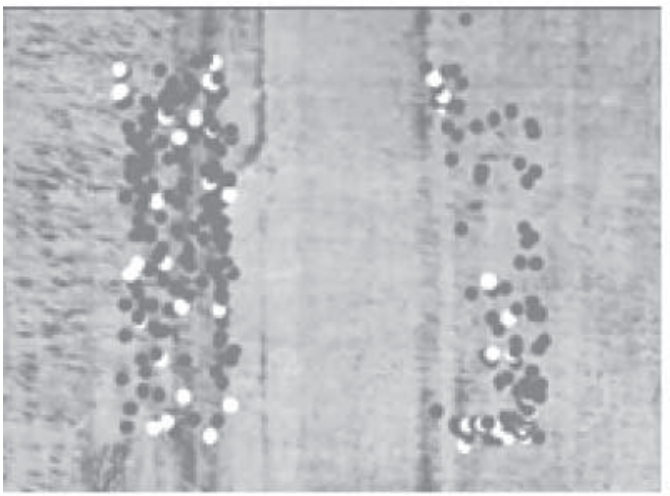

(c)

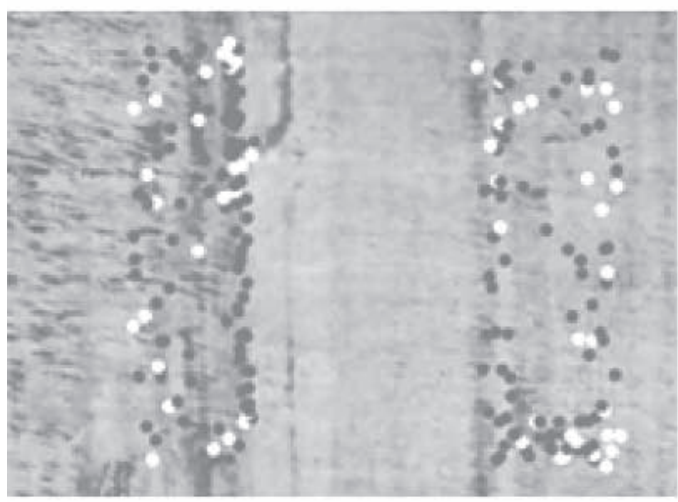

(e)

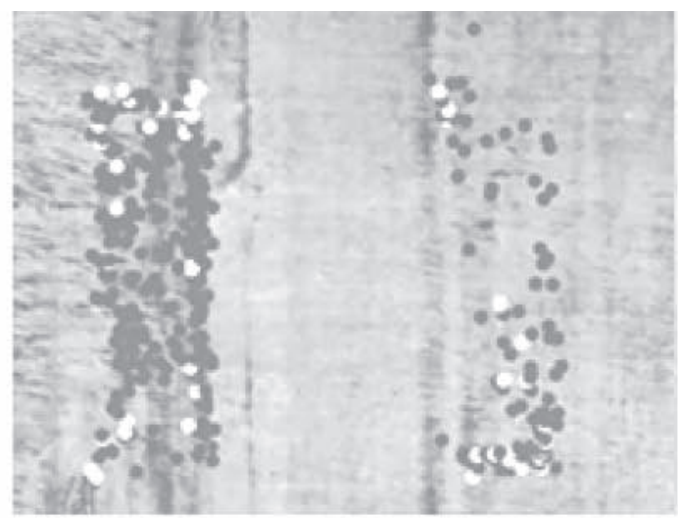

(b)

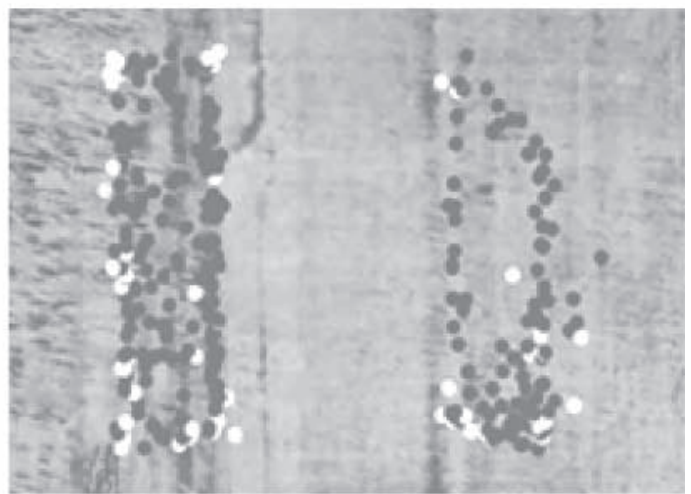

(d)

Figure 1. Heifer movements in the pastures recorded for $9 \mathrm{~h} / \mathrm{d}(0700$ to $1600 \mathrm{~h}$ ) in yr 2 (2009). Each dot represents the movement of the heifer as detected by a global positioning system unit. The left side of the pictures depicts movements of heifers assigned to the grazing on pasture (PST) in yr 1 and 2 (PSTPST) treatment, whereas the picture on the right shows movements of a heifer that had not been exposed to PST [i.e., the heifer was in confinement (CNF)] the previous year (CNFPST treatment). (a) d 1; (b) d 2; (c) d 3; (d) d 4; (e) d 5. PSTPST represents cows that grazed as heifers in 2008 and 2009; PSTCNF represents heifers that grazed in 2008 and 2010.

$\mathrm{d}$ on pasture, inexperienced (CNFCNF) cows showed the same grazing patterns as experienced cows.

Cows from all treatments appeared to be affected by heat stress. They decreased grazing time and increased time standing and drinking water during the hottest day of the trial (d 33). On this day, the PSTCNF cows displayed less $(P<0.05)$ grazing time compared with cows assigned to other treatments. We could not find any specific reason why PSTCNF cows were more affected by high temperatures than other cows. The biomass in the paddocks where PSTCNF cows were allocated did not differ from biomass in the paddocks 


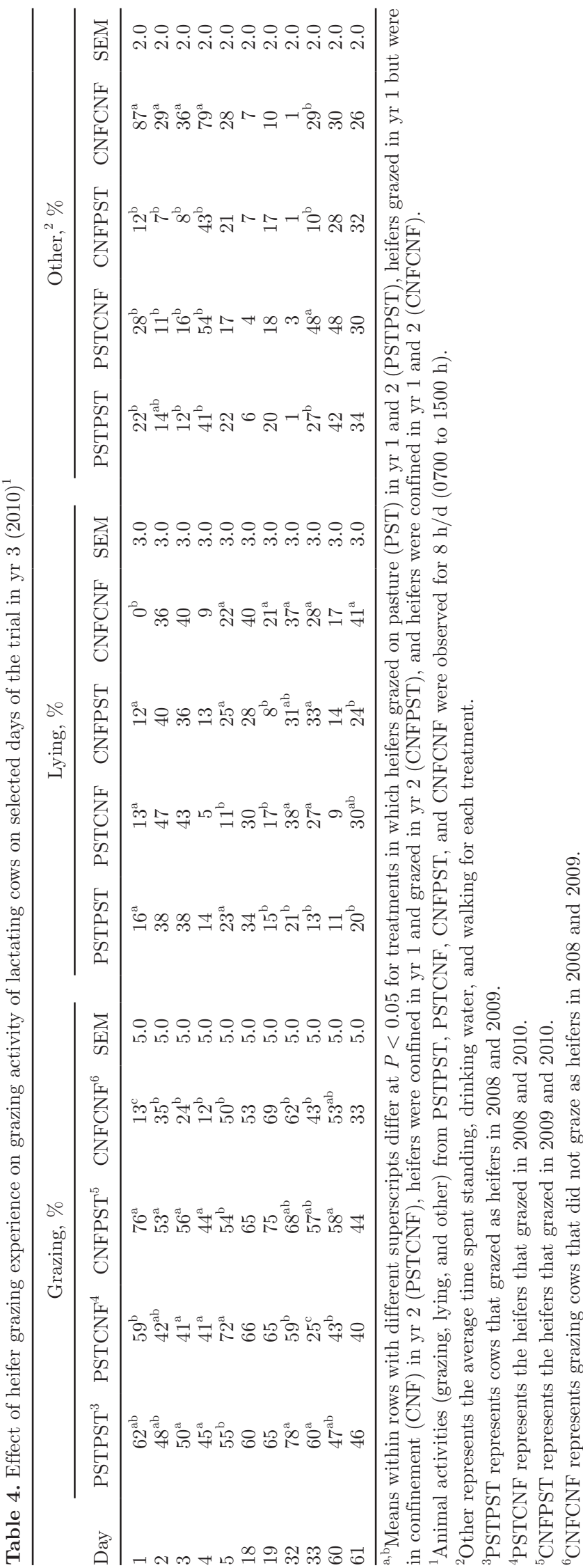

where the PSTPST, CNFPST, and CNFCNF cow groups were allocated $(19.6,19.0,20.5$, and $20.3 \mathrm{~kg}$ of $\mathrm{DM} /$ cow per day, respectively). Times spent lying on $\mathrm{d}$ 1 were similar to yr 2 , in which the inexperienced heifers did not lie down during $\mathrm{d} 1$. For yr 3 , the inexperienced (CNFCNF) cows spent $8 \mathrm{~h}$ in the pasture without lying down (Table 4). Differences in time spent lying down among treatments were observed on d 5, 19, 32, 33, and 61 . The time spent for other activities, such as drinking, standing, and walking, was significantly different among treatments on d 1, 2, 3, 4, and 33 (Table 4). Those differences were affected by the reduced time spent grazing by CNFCNF cows during the first $4 \mathrm{~d}$ of the trial, and by PSTCNF cows on d 33. Table 5 shows that the number of other activities increased by d 33; with increased air temperature and decreased forage availability, cows spent more time drinking water and standing.

The average distance traveled for PSTPST, PSTCNF, CNFPST, and CNFCNF cows during the 8-h observation period in yr 3 are reported in Table 5. No differences were found among treatments during the first $3 \mathrm{~d}$ of the experiment. However on d 4, distances walked were $5.1,3.2,2.6$, and $1.6 \mathrm{~km}$ for PSTPST, PSTCNF, CNFPST, and CNFCNF cows, respectively, with PSTPST cows walking more $(P<0.05)$ than CNFPST and CNFCNF cows. On d 4, PSTCNF and CNFCNF cows returned from confinement, and PSTPST and CNFPST cows were allocated to a new paddock. Cows from the PSTPST treatment, who grazed for $3 \mathrm{yr}$, seemed to explore more (travel longer distances) when introduced to the new environment. Also, the distance walked by PSTPST cows increased at the end of the experimental period; this was likely due to the reduced biomass in the paddocks where that treatment was allocated.

The movement patterns of one representative cow from each treatment for $\mathrm{d} 1,2,4$, and 30 during $\mathrm{yr}$ 3 of the study are presented in Figures 2, 3, 4, and 5, respectively. Cow groups that grazed as heifers during yr 2 (PSTPST and CNFPST) exhibited similar patterns of movement that were distinctly different than those from cows that did not graze as heifers (PSTCNF and CNFCNF) during yr 2 (Figure 2). Cows from the PSTPST and CNFPST groups explored more of the paddock compared with PSTCNF and CNFCNF cows, which spent almost the entire 8-h observation time in close proximity to the paddock gate (Figure 2). We observed the same situation during yr 2, when the experienced (PSTPST) heifer group explored the whole paddock while the inexperienced (CNFPST) heifers spent large amounts of time in the same place. On d 2, PSTCNF cows showed the same movement pattern in the pastures as PSTPST and CNFPST cows, but the 
Table 5. Average of distance $(\mathrm{km})$ walked for lactating cows on selected days of the trial in yr $3(2010)$

\begin{tabular}{lccccc}
\hline & \multicolumn{5}{c}{ Distance,$~^{1} \mathrm{~km}$} \\
\cline { 2 - 5 } Day & PSTPST $^{2}$ & PSTCNF $^{3}$ & CNFPST $^{4}$ & CNFCNF $^{5}$ & SEM \\
\hline 1 & 4.9 & 4.6 & 5.2 & 3.2 & 1.0 \\
2 & 3.7 & 3.6 & 2.6 & 3.8 & 0.9 \\
3 & 1.6 & 3.2 & 3.7 & 2.6 & 1.4 \\
4 & $5.1^{\mathrm{a}}$ & $3.2^{\mathrm{ab}}$ & $2.6^{\mathrm{b}}$ & $1.6^{\mathrm{b}}$ & 1.3 \\
5 & 4.4 & 2.6 & 2.6 & 3.0 & 1.1 \\
18 & 3.0 & 2.6 & 1.8 & 2.0 & 1.4 \\
32 & 2.0 & 2.7 & 2.1 & 1.6 & 1.4 \\
33 & 3.5 & 1.7 & 1.5 & $0.7^{\mathrm{b}}$ & 1.0 \\
60 & $3.9^{\mathrm{a}}$ & $1.9^{\mathrm{ab}}$ & $1.5^{\mathrm{ab}}$ & 2.0 & 1.8 \\
61 & 4.5 & 4.0 & 2.7 & & \\
\hline
\end{tabular}

${ }^{\mathrm{a}, \mathrm{b}}$ Means within rows with different superscripts differ at $P<0.05$ for treatments in which heifers grazed on pasture (PST) in yr 1 and 2 (PSTPST), heifers grazed in yr 1 but were in confinement (CNF) in yr 2 (PSTCNF), heifers were confined in yr 1 and grazed in yr 2 (CNFPST), and heifers were confined in yr 1 and 2 (CNFCNF).

${ }^{1}$ Average of kilometers walked during $8 \mathrm{~h} / \mathrm{d}(0700$ to $1500 \mathrm{~h})$ for treatments PSTPST, PSTCNF, CNFPST, and CNFCNF.

${ }^{2}$ PSTPST represents cows that grazed as heifers in 2008 and 2009.

${ }^{3}$ PSTCNF represents the heifers that grazed in 2008 and 2010.

${ }^{4}$ CNFPST represents the heifers that grazed in 2009 and 2010

${ }^{5}$ CNFCNF represents grazing cows that did not graze as heifers in 2008 and 2009.

CNFCNF cows continued to limit their grazing activities to the area nearest the paddock gate. After $4 \mathrm{~d}$ of exposure to pasture, cows on all treatments had similar movements during the $8 \mathrm{~h}$ of observation (Figure 5).

\section{Milk Production and Composition}

During d 1, cows that had not grazed as heifers during yr 2 (PSTCNF and CNFCNF), produced less milk than cows that had grazed as heifers during yr 2
(PSTPST and CNFPST). The milk yield for $\mathrm{d} 1$ was $32.6,28.2,32.9$, and $28.8 \mathrm{~kg}$ for PSTPST, PSTCNF, CNFPST, and CNFCNF cows, respectively (Table 6). The following days (d 2 and 3), yields of milk were less $(P<0.05)$ for cows with no previous grazing experience (CNFCNF), than for groups that grazed as heifers (PSTPST and CNFPST) during yr 2; this was most likely caused by the lower percentage of the time spent grazing. However, average daily milk production during the whole study (Table 7) was 30.5, 30.1,

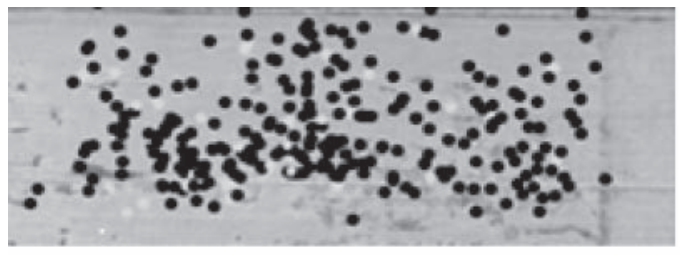

(a)

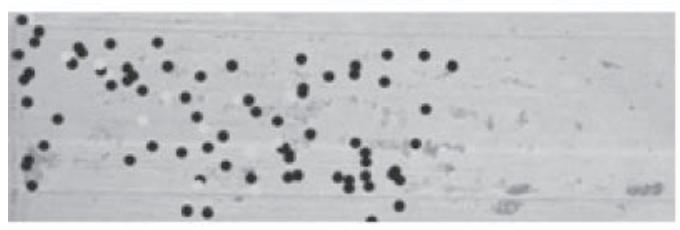

(c)

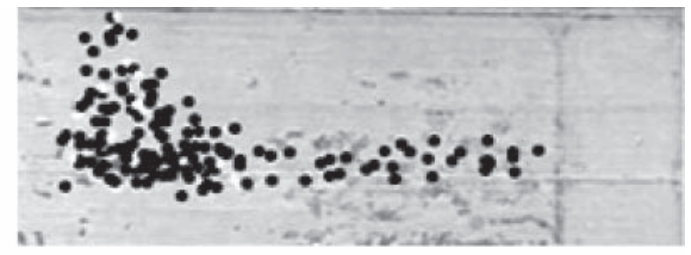

(b)

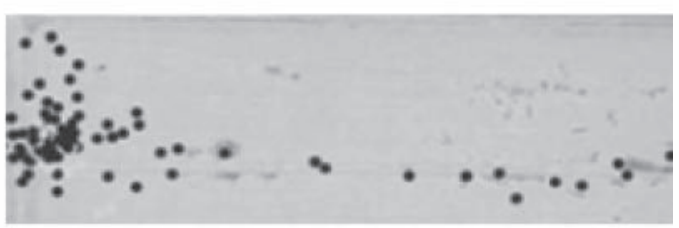

(d)

Figure 2. Movement of primiparous cows in the pastures recorded for $8 \mathrm{~h}$ on d 1 in yr 3 (2010). (a) Heifers assigned to grazing on pasture (PST) in yr 1 and 2 (PSTPST); (b) heifers grazed in yr 1, but in confinement (CNF) in yr 2 (PSTCNF); (c) heifers confined in yr 1 and grazed in yr 2 (CNFPST); (d) heifers confined in yr 1 and 2 (CNFCNF). PSTPST represents cows that grazed as heifers in 2008 and 2009; PSTCNF represents the heifers that grazed in 2008 and 2010; CNFPST represents the heifers that grazed in 2009 and 2010; CNFCNF represents grazing cows that did not graze as heifers in 2008 and 2009. 


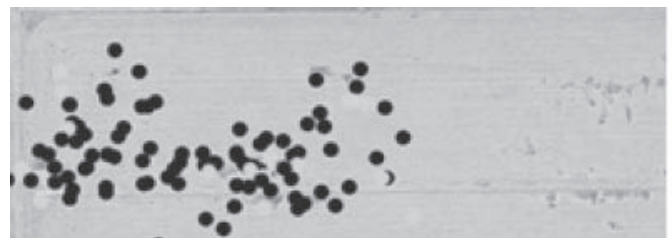

(a)

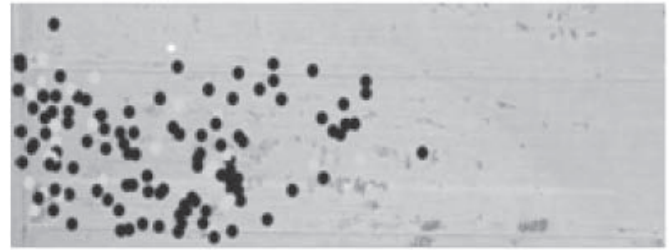

(c)

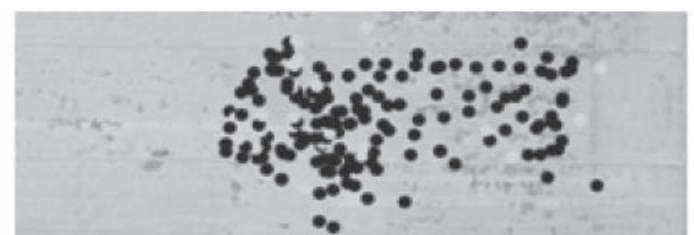

(b)

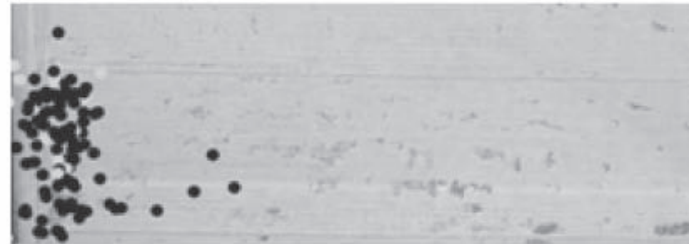

(d)

Figure 3. Movement of primiparous cows in the pastures recorded for $8 \mathrm{~h}$ on d 2 in yr 3 (2010). (a) Heifers assigned to grazing on pasture (PST) in yr 1 and 2 (PSTPST); (b) heifers grazed in yr 1, but in confinement (CNF) in yr 2 (PSTCNF); (c) heifers confined in yr 1 and grazed in yr 2 (CNFPST); (d) heifers confined in yr 1 and 2 (CNFCNF). PSTPST represents cows that grazed as heifers in 2008 and 2009; PSTCNF represents the heifers that grazed in 2008 and 2010; CNFPST represents the heifers that grazed in 2009 and 2010; CNFCNF represents grazing cows that did not graze as heifers in 2008 and 2009.

31.5, and $29.6 \mathrm{~kg}$ for PSTPST, PSTCNF, CNFPST, and CNFCNF cows, respectively, with no difference $(P$ $>0.05)$ among cow groups. Also, no differences $(P>$ $0.05)$ were detected for milk composition among treatments. Daily milk yield, SCM yield, and fat and protein percentages averaged across treatments were $30.4 \mathrm{~kg}$, $23.0 \mathrm{~kg}, 3.5 \%$, and 2.9\%, respectively. Grazing studies (Reis and Combs, 2000) conducted similarly with high-producing dairy cows grazing alfalfa and ryegrass pasture and supplemented with $10 \mathrm{~kg} / \mathrm{d}$ of a corn-based concentrate exhibited a similar average of daily milk

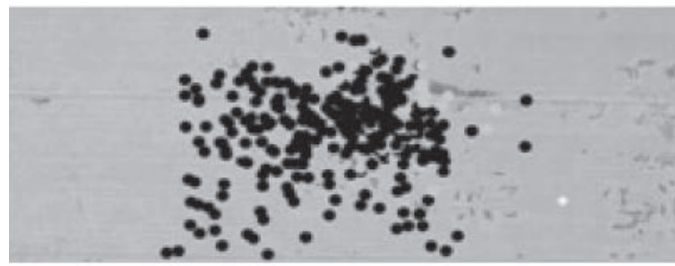

(a)

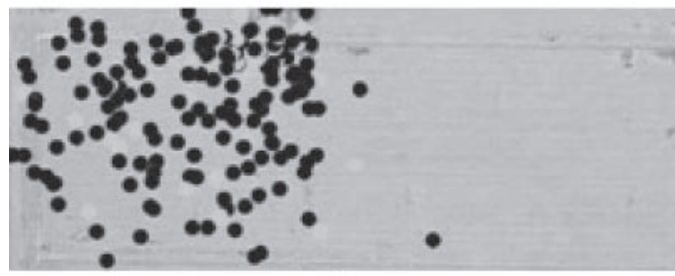

(c) yield, and milk fat and protein percentages $(30.4 \mathrm{~kg} / \mathrm{d}$, $3.08 \%$, and $3.05 \%$, respectively). In the present study, milk yield was within the range reported by Muller and Fales (1998), when cows consumed 11.4 to $15 \mathrm{~kg}$ of $\mathrm{DM} / \mathrm{d}$ from pasture and 7.3 to $8.6 \mathrm{~kg}$ of concentrate $\mathrm{DM} / \mathrm{d}$.

In general, cows lost BW during the experiment (Table 7). Changes in BW were -48.0, -36.4, -65.4, and $-55.1 \mathrm{~kg}$ for PSTPST, PSTCNF, CNFPST, and CNFCNF cows, respectively, with CNFPST cows losing significantly more BW than PSTCNF cows. At the be-

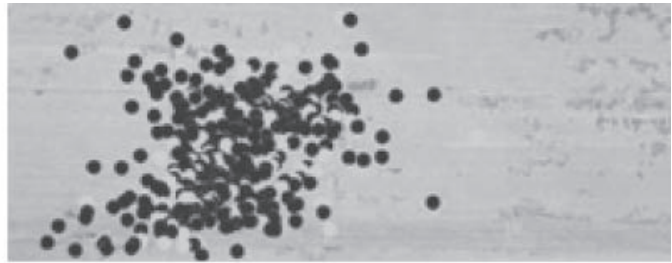

(b)

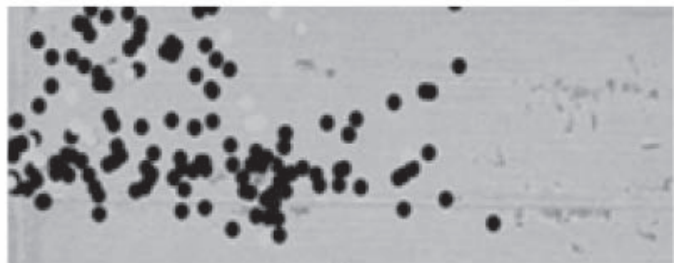

(d)

Figure 4. Movement of primiparous cows in the pastures recorded for $8 \mathrm{~h}$ on d 4 in yr 3 (2010). (a) Heifers assigned to grazing on pasture (PST) in yr 1 and 2 (PSTPST); (b) heifers grazed in yr 1, but in confinement (CNF) in yr 2 (PSTCNF); (c) heifers confined in yr 1 and grazed in yr 2 (CNFPST); (d) heifers confined in yr 1 and 2 (CNFCNF). PSTPST represents cows that grazed as heifers in 2008 and 2009; PSTCNF represents the heifers that grazed in 2008 and 2010; CNFPST represents the heifers that grazed in 2009 and 2010; CNFCNF represents grazing cows that did not graze as heifers in 2008 and 2009. 


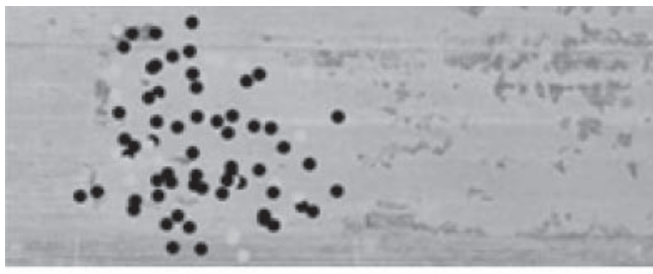

(a)

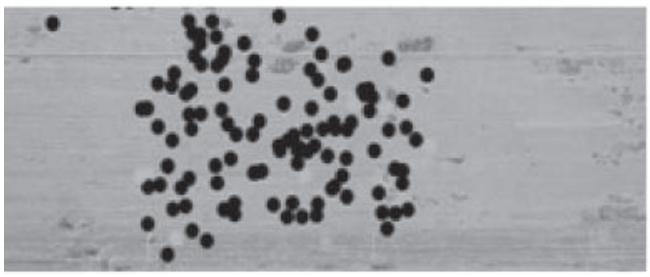

(c)

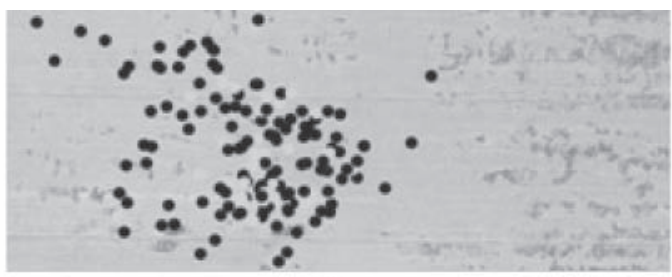

(b)

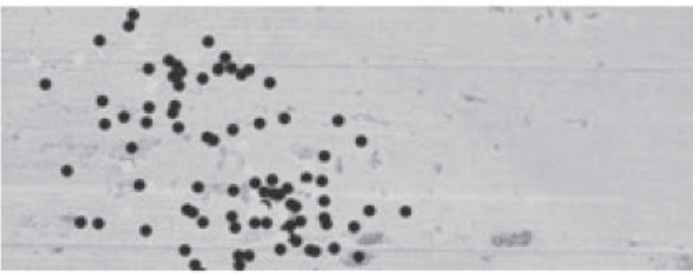

(d)

Figure 5. Movement of primiparous cows in the pastures recorded for $8 \mathrm{~h}$ on d 30 in yr 3 (2010). (a) Heifers assigned to grazing on pasture (PST) in yr 1 and 2 (PSTPST); (b) heifers grazed in yr 1, but in confinement (CNF) in yr 2 (PSTCNF); (c) heifers confined in yr 1 and grazed in yr 2 (CNFPST); (d) heifers confined in yr 1 and 2 (CNFCNF). PSTPST represents cows that grazed as heifers in 2008 and 2009; PSTCNF represents the heifers that grazed in 2008 and 2010; CNFPST represents the heifers that grazed in 2009 and 2010; CNFCNF represents grazing cows that did not graze as heifers in 2008 and 2009.

ginning of yr 3, mean respective BW were 576, 575, 607, and $575 \mathrm{~kg}$. At the end of the trial, cows weighed 528 , 538,541 , and $520 \mathrm{~kg}$ for the same treatment groups.

\section{General Discussion}

Results from this study show that experience early in life of dairy heifers grazing high quality pasture does affect grazing behavior and milk production but only during the first few days of exposure to pasture. It appeared, however, that those cows with no previous grazing experience adapt relatively quickly to grazing and, as a result, milk production recovers within a few days.

Data from yr 2 showed that even a short exposure period (PSTPST and PSTCNF) when heifers were 6 mo old affected the grazing behavior compared with the inexperienced heifers (CNFPST). Heifers with

Table 6. Average of milk production for primiparous cows on selected days of the trial in yr $3(2010)^{1}$

\begin{tabular}{lcccc}
\hline & \multicolumn{3}{c}{ Milk yield, kg } \\
\cline { 2 - 5 } Day & PSTPST $^{2}$ & PSTCNF $^{3}$ & CNFPST $^{4}$ & CNFCNF $^{5}$ \\
\hline 1 & $32.6^{\mathrm{a}}$ & $28.2^{\mathrm{b}}$ & $32.9^{\mathrm{a}}$ & $28.8^{\mathrm{b}}$ \\
2 & $29.0^{\mathrm{a}}$ & $28.8^{\mathrm{a}}$ & $31.6^{\mathrm{a}}$ & $25.0^{\mathrm{b}}$ \\
3 & $30.8^{\mathrm{ab}}$ & $27.5^{\mathrm{bc}}$ & $32.1^{\mathrm{a}}$ & $26.6^{\mathrm{c}}$ \\
4 & 29.2 & 31.9 & 31.0 & 29.2 \\
5 & 28.6 & 29.5 & 30.3 & 25.8 \\
18 & 24.7 & 27.1 & 26.7 & 26.9 \\
32 & $24.4^{\mathrm{b}}$ & $25.6^{\mathrm{b}}$ & $29.1^{\mathrm{a}}$ & 27.1 \\
33 & 24.0 & 27.0 & 28.4 & $27.2^{\mathrm{ab}}$ \\
60 & 27.1 & 28.2 & 29.8 & 27.9 \\
61 & 27.5 & 27.6 & 31.1 & \\
\hline
\end{tabular}

${ }^{\mathrm{a}-\mathrm{c}}$ Means within rows with different superscripts differ at $P<0.05$ for treatments in which heifers grazed on pasture (PST) in yr 1 and 2 (PSTPST), heifers grazed in yr 1 but were in confinement (CNF) in yr 2 (PSTCNF), heifers were confined in yr 1 and grazed in yr 2 (CNFPST), and heifers were confined in yr 1 and 2 (CNFCNF)

${ }^{1}$ The SEM $=1.14$.

${ }^{2}$ PSTPST represents cows that grazed as heifers in 2008 and 2009.

${ }^{3}$ PSTCNF represents the heifers that grazed in 2008 and 2010.

${ }^{4}$ CNFPST represents the heifers that grazed in 2009 and 2010 .

${ }^{5} \mathrm{CNFCNF}$ represents grazing cows that did not graze as heifers in 2008 and 2009. 
Table 7. Average of milk production and milk composition for primiparous cows for the lactation phase (61 d) of the trial

\begin{tabular}{lcccccc}
\hline & \multicolumn{7}{c}{ Treatment } & & \\
\cline { 2 - 5 } Item & PSTPST $^{1}$ & PSTCNF $^{2}$ & CNFPST $^{3}$ & CNFCNF $^{4}$ & SEM & $P$-value \\
\hline Milk, kg/d & 30.5 & 30.1 & 31.5 & 29.6 & 1.0 & 0.64 \\
$4 \% \mathrm{FCM}, \mathrm{kg} / \mathrm{d}$ & 28.1 & 27.7 & 28.5 & 27.4 & 1.0 & 0.88 \\
$\mathrm{SCM}, \mathrm{kg} / \mathrm{d}$ & 23.2 & 22.6 & 23.5 & 22.6 & 1.2 & 0.94 \\
$\mathrm{ECM}, \mathrm{kg} / \mathrm{d}$ & 30.0 & 29.4 & 30.4 & 29.2 & 1.1 & 0.88 \\
Fat, $\%$ & 3.4 & 3.5 & 3.4 & 3.5 & 0.0 & 0.24 \\
Fat, $\mathrm{kg} / \mathrm{d}$ & 1.1 & 1.0 & 1.1 & 1.0 & 1.0 & 0.64 \\
Protein, \% & 3.0 & 3.0 & 2.9 & 3.0 & 0.1 & 0.80 \\
Protein, $\mathrm{kg} / \mathrm{d}$ & 0.9 & 0.8 & 0.9 & 0.8 & 0.0 & 0.87 \\
BW change, $\mathrm{kg} / 61 \mathrm{~d}$ & $-48.0^{\mathrm{ab}}$ & $-36.4^{\mathrm{b}}$ & $-65.4^{\mathrm{a}}$ & $-55.1^{\text {ab }}$ & 10.3 & 0.05 \\
\hline
\end{tabular}

${ }^{\mathrm{a}, \mathrm{b}}$ Means within rows with different superscripts differ at $P<0.05$ for treatments in which heifers grazed on pasture (PST) in yr 1 and 2 (PSTPST), heifers grazed in yr 1 but were in confinement (CNF) in yr 2 (PSTCNF), heifers were confined in yr 1 and grazed in yr 2 (CNFPST), and heifers were confined in yr 1 and 2 (CNFCNF).

${ }^{1}$ PSTPST represents cows that grazed as heifers in 2008 and 2009.

${ }^{2}$ PSTCNF represents the heifers that grazed in 2008 and 2010.

${ }^{3} \mathrm{CNFPST}$ represents the heifers that grazed in 2009 and 2010.

${ }^{4}$ CNFCNF represents grazing cows that did not graze as heifers in 2008 and 2009.

grazing experience appeared to remember how to graze immediately when allocated to a pasture in the second year. However, inexperienced heifers (CNFPST) exhibited similar grazing times as experienced heifers after $1 \mathrm{~d}$. These data support the findings of Lobato et al. (1980) who observed that young animals accept a new environment and a novel food easily during the first year of life. Lobato et al. (1980) also observed that the desire to consume a novel food decreases in mature animals, making it difficult to introduce new foods later in life. This may explain why heifers that grazed for the first time as cows (CNFCNF) took $3 \mathrm{~d}$ to show similar behavior and milk production compared with cows that had previous grazing experiences as heifers (PSTPST, PSTCNF, and CNFPST).

The interval that heifers remained in confinement housing could also affect grazing memory. Larry et al. (1999) observed that cattle were able to remember where they had foraged after delays of up to $8 \mathrm{~h}$, but performed poorly after delays of $12 \mathrm{~h}$. In the present trial, heifers (PSTCNF) that were initially exposed to a grazing environment when 6 mo old, and after being in confinement for $18 \mathrm{mo}$, showed similar grazing behavior as cows that grazed as heifers for both years. These data suggest that longer-term factors of memory are at play.

This study demonstrates that initial adaptation to a new environment occurs over the first few days, and productivity of inexperienced animals is diminished in those days but recovers quickly thereafter. These observations can be explained by the improvement of grazing skills that are made on the basis of information gained from repeated performance (Bandura, 1977).
Also, all animals appeared to adjust to pasture as the summer progressed. In yr 2, experienced and inexperienced heifers showed a similar behavior (time spent grazing and distance walked) after d 8 when the daily forage availability changed from 30 to $15 \mathrm{~kg}$ of DM/ head per day as the summer progressed. Also in yr 3, experienced and inexperienced lactating cows walked a similar distance and had similar milk production when forage availability decreased from 30 to $20 \mathrm{~kg}$ of DM/ head per day after d 18. According to Arave and Albright (1981), when forage availability is not sufficient to meet animal demands, animals tend to spend more time grazing and walk longer distances looking for food. In this study, forage availability was greater than animal demand. This was part of the experimental design because we wanted to look specifically at how animal experience affects grazing behavior, and we wanted to minimize the effects of low pasture supply on animal behavior.

A GPS system was used in this study to evaluate heifer movement patterns in the pasture. The GPS system was very effective at defining differences in animal movement between experienced and inexperienced heifers during the first week in the pasture. The way that heifers with grazing experience moved in the pasture is best explained as spatial memory. Experienced animals appeared to remember how to graze by simple exploration of the pasture (Larry et al., 1999), whereas inexperienced animals tended not to move away from pasture introductory points. According to Larry et al. (1999) animals moved from one pasture to a new environment have the tendency to graze in the same direction they usually grazed in the previous environ- 
ment. In the present study, heifers in yr 2 grazed in a south to north direction, but in yr 3 the same heifers as cows grazed in an east to west direction. Figures 1 and 2 show that direction did not influence grazing activity of experienced heifers. The average kilometers walked for heifers (yr 2) and lactating cows (yr 3) were not different (2.7 vs. 2.9 , respectively; $P>0.05$ ); but, the movement patterns did change from yr 2 to 3 . Heifers explored the entire paddock more frequently as yearlings (Figure 1) than as lactating cows (Figures 2, 3, 4 and 5). Lactating cows explored the pasture more in the first day than the following days.

Also, inexperienced yearling heifers appear to behave differently than inexperienced lactating cows. After they adjusted to the pasture, inexperienced yearling heifers explored the entire paddock (Figure 1) in the same day. Inexperienced lactating cows, after they learned to graze, did not explore the entire paddock in the same day, as they moved according to the forage available in each spot. The differences in movement patterns in the pasture between heifers and lactating cows may be influenced by the difference in energy demand. It is important to consider that heifers and lactating cows were located in paddocks of approximately the same size $(\sim 0.50$ ha).

\section{CONCLUSIONS}

Grazing studies that use cattle normally managed in confinement should offer at least 1 wk to allow both experienced and inexperienced cattle to adapt to the grazing environment. Our results support that a short adaptation period $(10-14 \mathrm{~d})$ is adequate time for inexperienced animals to adjust to the new environment and recover milk production. Low-cost GPS proved to be an important tool to monitor grazing behavior and likewise can provide valuable data in dairy grazing studies. This equipment offers a quantitative way to measure how animals move in the pasture. The GPS data could offer insight into forage preferences by evaluating the time spent grazing the same type of forage. Global positioning system data also can monitor changes in animal behavior due to heat stress or other weather factors. In addition, monitoring of animal BW and movements recorded by GPS could provide quantitative data that can be important for studies that evaluate energy requirements of grazing animals. The special relationship between animal movements and forage availability could also be better understood with GPS technologies.

\section{ACKNOWLEDGMENTS}

Appreciation is extended to HATCH project WIS01539, NE-1044 multi-state research formula fund
Hatch Capacity - Grazing for funding this project to D. K. Combs. The authors thank the staff at Marshfield Agriculture Research Station (Marshfield, WI), Sandy Trower (Arlington Research Station, Arlington, WI) for animal care and trial management, and Peter Crump of the University of Wisconsin (Madison) College of Agricultural and Life Sciences (CALS) Computer Consulting Lab for assistance with statistical analysis of the data.

\section{REFERENCES}

AOAC International. 1995. Official Methods of Analysis. 16th ed. AOAC International, Arlington, VA.

Arave, C. W., and J. L. Albright. 1981. Cattle behavior. J. Dairy Sci. 64:1318-1329.

Arnold, G. W. 1970. Regulation of food intake in grazing ruminants. Pages 264-274 in Physiology of Digestion and Metabolism in the Ruminant. A. T. Phillipson, ed. Oriel Press, London, UK.

Arnold, G. W., and R. A. Maller. 1977. Effects of nutritional experience in early and adult life on the performance and dietary habits of sheep. Appl. Anim. Ethol. 3:5-26.

Bandura, A. 1977. Social learning theory. Prentice-Hall, Englewood Cliffs.

Bransby, D. I., A. G. Matches, and G. F. Krause. 1977. Disk meter for rapid estimation of herbage yield in grazing trials. Agron. J. 69:393-396.

Distel, R. A., and F. D. Provenza. 1991. Experience early in life affects voluntary intake of blackbrush by goats. J. Chem. Ecol. $17: 431-450$.

Flores, E. R., F. D. Provenza, and D. F. Balph. 1989. The effect of experience on the foraging skill of lambs: Importance of plant form. Appl. Anim. Behav. Sci. 23:285-291.

Gary, L. A., G. W. Sherritt, and E. B. Hale. 1970. Behavior of Charolais cattle on pasture. J. Anim. Sci. 30:203-206.

Gluesing, E. A., and D. F. Balph. 1980. An aspect of feeding behavior and its importance to grazing systems. J. Range Manage. $33: 426-427$.

Green, G. C., R. L. Elwin, B. E. Mottershead, and J. J. Lynch. 1984. Long term effects of early experience to supplementary feeding in sheep. Proc. Aust. Soc. Anim. Prod. 15:373-375.

Hatfield, P. G., L. Ortega-Reyes, F. D. Provenza, and H. A. Glimp. 1992. Post-exposure performance of lambs exposed to whole barley early in life. Sheep Res. J. 8:92-94.

Hodgson, J. 1971. The development of solid food intake in calves. 1. The effect of previous experience of solid food, and the physical form of the diet, on the development of food intake after weaning. Anim. Prod. 13:15-24.

Hodgson, J., and W. S. Jamieson. 1981. Variation in herbage mass and digestibility, and the grazing behavior and behavior and herbage intake of adult cattle and weaned calves. Grass Forage Sci. 36:39-57.

Larry, D. H., D. W. Bailey, and E. A. Laca. 1999. Pages 91-100 in Grazing Behavior of Livestock and Wildlife. Idaho Forest, Wildlife \& Range Exp. Sta. Bull. No. 70. K. L. Launchbaugh, K. D. Saunders, and J. C. Mosley, ed. Univ. of Idaho, Moscow.

Lobato, J. F. P., G. R. Pearce, and R. G. Beilharz. 1980. Effect of early familiarization with dietary supplements on the subsequent ingestion of molasses-urea blocks by sheep. Appl. Anim. Ethol. 6:149-161.

Muller, L. D., and S. L. Fales. 1998. Supplementation of cool-season grass pastures for dairy cattle. Page 335 in Grass for Dairy Cattle. J. H. Cherney and D. J. R. Cherney, ed. CABI Publishing, New York, NY.

NRC. 2001. Nutrient Requirements of Dairy Cattle. 7th rev. ed. Natl. Acad. Sci., Washington, DC.

Ortega-Reyes, L., and F. D. Provenza. 1993. Experience with blackbrush affects ingestion of shrub live oak by goats. J. Anim. Sci. 71:380-383. 
Ortega-Reyes, L., F. D. Provenza, C. F. Parker, and D. F. Balph. 1987. Performance in dry lot by lambs exposed to whole barleyprotein mineral pellet diet for different durations during the nursing period. J. Anim. Sci. 65 (Suppl. 1):445. (Abstr.)

Provenza, F. D. 1995. Origins of food preference in herbivores. Paper 29 in National Wildlife Research Center Repellents Conference. USDA National Wildlife Center Symposia. University of NebraskaLincoln.

Provenza, F. D., and J. C. Malechek. 1986. A comparison of food selection and foraging behavior in juvenile and adult goats. Appl. Anim. Behav. Sci. 16:49-61.

Ramos, A., and T. Tennessen. 1992. Effect of previous grazing experience on the grazing behavior of lambs. Appl. Anim. Behav. Sci. $33: 43-52$.
Reis, R. B., and D. K. Combs. 2000. Effects of corn processing and supplemental hay on rumen environment and lactation performance of dairy cows grazing grass-legume pasture. J. Dairy Sci. $83: 2529-2538$.

SAS Institute. 2004. User's Guide: Statistics. Version 9.1 ed. SAS Institute Inc., Cary, NC.

Van Soest, P. J., J. B. Robertson, and B. A. Lew. 1991. Methods for dietary fiber, neutral detergent fiber, and nonstarch polysaccharides in relation to animal nutrition. J. Dairy Sci. 74:3583-3597. 